\title{
Psychology and Mental Health Practice: A Crisis of Leadership
}

\author{
Mignone $\mathrm{T}^{1}$, Steffan $\mathrm{S}^{2}$, Weeks $\mathbf{W}^{2}$, Klostermann $\mathrm{K}^{2 *}$ and Peressotti \\ $\mathbf{M}^{2}$ \\ ${ }^{1}$ VA Western New York Healthcare System, 3495 Bailey Avenue, Buffalo, NY, USA \\ ${ }^{2}$ Medaille College, 18 Agassiz Circle, Buffalo, NY, USA
}

\section{Case Report}

Volume 3 Issue 3

Received Date: February 13, 2018

Published Date: March 20, 2018

*Corresponding author: Keith Klostermann, Medaille College, 18 Agassiz Circle, Buffalo, NY, USA, Tel: 14214; E-mail: kck35@medaille.edu

\section{Abstract}

Strong organizational leadership is widely recognized as an essential feature of successful organizations. While formal leadership training and educational programs have been embedded within many disciplines, the mental health and psychology fields have historically neglected the traditional aspects of leadership. Moreover, the lack of appropriate selection mechanisms for identifying qualified leadership candidates has resulted in a void of leadership and a failure to promote and foster professional growth that would turn the most talented individuals into successful leaders. The purpose of this brief report is to reflect on current leadership and promotion practices within psychology and mental health and provide recommendations for addressing this issue.

Keywords: Leadership; Promotion; Accountability; Complexity; Promoted

\section{Psychology and Mental Health Practice: A Crisis of Leadership}

Across multiple disciplines, strong organizational leadership is widely recognized as an essential feature of successful organizations. While formal leadership training and educational programs have been embedded within certain disciplines (e.g., business and industry, military), the mental health and psychology fields have historically neglected the traditional aspects of leadership. Moreover, the lack of appropriate selection mechanisms for identifying qualified leadership candidates has resulted in a void of leadership and a failure to promote and foster professional growth that would turn the most talented individuals into successful leaders. Although on the surface this may seem like an academic exercise, the lack of effective leadership in psychology and mental health has important implications for service delivery and patient care as well as therapist morale, professional development, and burnout. Moreover, poor leadership has a negative impact on the recruitment of highly trained therapists and retention of top performers.

The leadership vacuum may be, in part, based on several faulty assumptions including that experience is synonymous with leadership, and that visibility outweighs qualifications. There also exists insecurity among decision-makers that can prevent the hiring of highly skilled leaders, a general lack of accountability and leadership understanding at the hiring level, and active inertia. In addition to these faulty assumptions, an incorrect reductionist approach to dealing with dynamic complexity, an incomplete notion of who and what determines the "experts," a misguided and incorrect understanding of analysis expressed in the prevalent functional design of many organizations, and a 


\section{Psychology \& Psychological Research International Journal}

complementary lack of understanding and application of synthesis all prevent an organization from understanding itself at a higher order of cognition. If one of the defining qualities of leadership is to discover and capture the collective genius potentially found in any organization, then these faulty assumptions and these approaches that by design and application sub optimize the potential of any organization have to be exposed. Leaders need to be the intellectual caretakers of their organizations as well as their organizational architects. The purpose of this brief report is to reflect on each of these areas and concludes with recommendations for addressing this issue.

\section{Experience Equals Effectiveness}

Historically, there has been a belief in mental health treatment that extensive experience or individual success equates to successful leadership skills. Sadly, this is not the case. It is not the case for two reasons: 1 . expertise in mental health treatment may be the foundation for the traditional understanding of who is the "expert" but this expertise may only be in the actual subject matter itself, and 2. leadership is a meta discipline that is a subject matter in and of itself, which can be universally applied to any subject matter area. A similar assumption is made about clinical supervisor effectiveness in which years of experience are equated with effective supervisor behavior. The term "supervisor" comes from two Latin words: supra, which means above and videre, which means to see, and its contextual origin is in classical management theory. The supervisor was someone who was literally the best at doing something and therefore watched over all of the individuals doing what the supervisor did best. While experience in the field may be an important predictor of clinical effectiveness, it is not a measure of leadership ability. Unfortunately, many experienced clinicians have been ineffective leaders. Simply stated, success in one domain (e.g., therapy) does not guarantee or predict success in another (e.g., supervisor, manager).To use a sports analogy, a highly successful coordinator in football does not always translate to being an effective or successful head coach. The traditional notion of "expert" is a consequence of analysis, i.e. taking complexity and breaking it into its most indivisible pieces and summing knowledge of the parts into a so-called understanding of the whole, which is a very false conclusion. What analysis provides is knowledge of the part of the system perceived predominately independently of the system of which it is a part. Unfortunately, analysis has for all too many become synonymous with thought. These oversimplifications of leadership are most likely done out of convenience or as way to reward a staff member for their years of service (i.e., the "paid his/her dues" model) and certainly out of a misunderstanding of analysis and a lack of understanding of synthesis.

\section{Visibility versus Qualifications}

Another contributing factor to the void of leadership involves those individuals that are skilled at being visible and staying on people's radar, but without any substantive contributions to support their standing; in other words, these individuals are all "smoke and mirrors." Because these individuals are effective at garnering favor among important decision-makers they are often viewed more favorably based on the optics of being in the right place at the right time. Moreover, individuals promoted and selected to leadership positions may not be the most highly qualified, but may be the most politically expedient choice for the organization at that particular time.

\section{Insecurity among Decision-Makers}

Given the argument that many in leadership positions are not highly effective leaders, these individuals may fail to recognize therapist accomplishments (both big and small) and also deny qualified staff opportunities out of fear of being challenged or being perceived as ineffective in comparison to more effective leaders. The basic mentality among these leaders when hiring for other leadership positions is to identify people who will do well, but not too well to make others look bad. There is protection of the "in-group" and who is selected to be part of this inner circle. This is the consequence of several misconceptions of leadership. Leadership is not about sub optimizing the potential of an organization, which is this intentional dumbing down of the organization to order to prevent substantive conflict within the organization. As Margaret Wheatley (2006) expresses, an organization is near death when it is at a status quo existence [1]. The dynamic organization must have feedback and share this feedback throughout the organization. This is one of the design features that an organization's leadership creates and promotes. This is what produces change and leadership is about change. Leading is always preparing an organization for its next new reality. Another misconception about leadership is further evidenced in Jack Welch's idea of a leader as a gardener who has a can of water in one hand and a can of fertilizer in the other and distributes each in his garden. Some flowers will grow and some will grow with more color and fragrance than the others. These will get more water and fertilizer 


\section{Psychology \& Psychological Research International Journal}

to realize their full potential. These would be Welch's "A" players who he counted on to take the organization to the next level. What was described in the beginning of this paragraph would be an anathema to Jack Welch (for more information, see: https://jackwelch.strayer.edu).

\section{Lack of Accountability among Decision- Makers}

Unfortunately, qualified leadership candidates are not selected, in part, because of a lack of accountability among those tasked with making these decisions. Oftentimes there is no formal review mechanism for the effectiveness of the selection process as well as the criteria used to select the individual. Even in cases where there are standardized processes (hiring committees, rubrics, etc.), there is usually a designated hiring official or senior member whose decision is more weighted than others.

\section{Inertia}

Although there may be an expressed and explicit desire for change and recognition that more effective leadership is needed, when the realities of needed changes are carefully considered, many will default to a more-of-the same mentality rather than being willing to try to a different approach or style. There is comfort in the familiar, which results in decision-makers often selecting individuals with similar styles who will not challenge the current status quo; these individuals are very good at "making the trains run on time" and typically are not known for their creativity or vision.

\section{Recommendations}

Welch set an example of transformational leadership in which a leader inspires others to work together towards a common goal without coercion. This transformational leadership model is the key to creating a learning organization; an organization continually committed to creating its own future. According to Welch there are three critical components of any successful organization, i.e. leading, learning, and change. These parts of a learning organization find their essential properties in their interactions. It is our contention that learning organizations (including those in which psychologists and mental health providers function) must have leaders who understand transformational processes therefore understanding their pivotal role in having the organization consistently poised for the ongoing and dynamic process of "becoming." The next two components of this proposed framework - learning and change - provide the process that leaders must employ to prepare their organizations for any new direction. The active definition of learning is the acquisition of new knowledge that is at least taken out for a test drive. This connects thinking and acting as essential interactions for any evaluative exercise of the usefulness of new knowledge. Taken as a whole, the information gleaned from a positive evaluation of theory and practice working interactively (i.e., evidence-based practice) can be used to inform clinical decision-making, improve service delivery, and justify cost expenditures.

The two models proposed in this paper are from two very different sources yet the models are interconnected due to Dr. W. Edwards Deming's knowledge of the work of Clarence Irving Lewis, the American pragmatist who could be mentioned in the same breath as William James, Charles Pierce, and John Dewy. The two models combine a very heavy philosophical ancestry in Lewis' proposition of what he called Conceptual Pragmatism as written in Lewis' 1929 book, Mind and the world order with the very practical and applicable instrument that grew out of Deming's reading of Lewis' book. Simply stated, this instrument integrates four elements of theory and practice: Plan, Do, Study, and Act.

Lewis' idea of Conceptual Pragmatism combines theory and application. It brings an a priori concept that acts as a rule of interpretation or a lens to what Lewis called the "given", i.e. the selection of sense data that the a priori concept will interpret. This very formal and philosophical presentation of Conceptual Pragmatism can be more easily understood in Lewis' comment that "philosophy is so to speak the mind's own study of itself in action." We propose that this definition of philosophy is a useful and dynamic heuristic for any learning organization. Deming not only agreed with Conceptual Pragmatism's philosophical underpinnings but also saw its extreme practicality in the learning and change process.

Welch had a clear passion for change, performance and excellence with a clear vision of the company in the future. Furthermore, he took time to view the organization as an interrelated system, rather than by its parts. He stressed the importance of having a clear vision and plan, but being willing to modify the plan based on feedback from his employees; another important management idea shared by these theorists.

Jonathan Gosling and Henry Mintzberg (2003) in The Five Minds of a Manager asserted five perspectives that managers who prove to be successful adhere to [2]. These 


\section{Psychology \& Psychological Research International Journal}

perspectives were inclusive of Welch's oversight of GE. They included 1) Managing self: reflective mindset, 2) Managing organizations: the analytic mind-set, 3) Managing context: the worldly mind-set, 4) Managing relationships: the collaborative mind-set, and 5) Managing change: the action mind-set. Gosling and Mintzberg characterized reflection as the "space between experience and explanation, where the mind makes the connections." If life is simply a series of happenings, some planned and some emergent experienced without explanation, or in other words without understanding, experiences do not create meaning. Leadership must be devoted to creating meaning; it is one of its most essential activities. The analytic mind set in the minds of both authors tries to get beyond the more superficial denotation of analysis and its Cartesian reductionist intellectual ancestry and to a more synthetic understanding of systems and structures and their roles in dealing with dynamic complexity. The worldly mindset may be in concert with what Margaret Wheatley has taught and that is to "think globally but act locally." In other words, systems thinkers need to be big picture thinkers with the appreciation that they may be only able to act locally to affect an intentioned result in the larger system of which they are a part. In disciplines as fluid and dynamic as mental health and psychology, it is imperative that organizations take on both a collaborative and growth mindset to provide an environment that supports acquisition and application of new knowledge. Individuals who are a part of a true learning organization feel as if they are a part of something greater than themselves; that they are members of a productive team. These types of organizations foster an environment in which collaborative learning among the parts improves the "whole." Employees are meant to be active participants interacting with one another in the pursuit of knowledge. The environment of a learning organization allow time for (and is supportive of) reflection and analysis, with open boundaries and free flowing information. Learning organizations must provide an environment that is conducive to learning. There must be time for reflection and analysis, strategic planning, understanding customer needs, evaluation of current work processes, and developing new products. In the quest to facilitate learning, an organization should prioritize employees need possessive schedules so they are able to take part in the learning process. Senge also recommends that employees receive training in core learning skills to make time dedicated to knowledge acquisition more productive.

To be clear, the areas listed above are based on our diverse observations, experiences, and consultation with seasoned colleagues and are best conceived at a general level, rather than a micro level of abstraction. These concerns are not meant to be exhaustive and should not be considered mutually exclusive but viewed interactionally with each possibly influencing the others. The implications of these hiring practices have important consequences for the quality of patient care, individual and professional growth of therapists, and ultimately the continued evolution of the field. Perhaps most important, from a system's perspective, inefficiency at one or more levels/parts of the system results in decreased productivity for the organization as a whole.

\section{References}

1. Wheatley MJ (2006) Leadership and the New Science: Discovering Order in a Chaotic Word. Berrett-Koehler Publishers: San Francisco, CA.

2. Gosling J, Mintzberg $\mathrm{H}$ (2003) The five minds of a manager. Harv Bus Rev 81(11): 54-63. 